\title{
A produção de guias de viagem por intelectuais brasileiros: um ensaio
}

\author{
Amanda Danelli Costa
}

\section{SciELO Books / SciELO Livros / SciELO Libros}

COSTA, A. D. A produção de guias de viagem por intelectuais brasileiros: um ensaio. In: MARAFON, G. J., FACCIOLI, M., and SÁNCHEZ, M. A., ed. Patrimônio, território e turismo no Brasil, Costa Rica e Itália [online]. Rio de Janeiro: EDUERJ, 2020, pp. 161-177. ISBN: 978-6500-03032-7. https://doi.org/10.7476/9786500030327.0008.

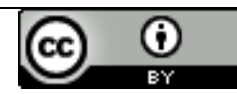

All the contents of this work, except where otherwise noted, is licensed under a Creative Commons Attribution 4.0 International license.

Todo o conteúdo deste trabalho, exceto quando houver ressalva, é publicado sob a licença Creative Commons Atribição 4.0.

Todo el contenido de esta obra, excepto donde se indique lo contrario, está bajo licencia de la licencia Creative Commons Reconocimento 4.0. 


\section{A produção de guias de viagem por intelectuais brasileiros: um ensaio}

Amanda Danelli Costa ${ }^{1}$

\section{Introdução: à guisa de uma apresentação do tema}

O presente ensaio tem como tema principal a produção de guias de viagem por intelectuais brasileiros na primeira metade do século XX, em específico os quatro guias a seguir: Guide des Etats-Unis du Brésil (1904), de Olavo Bilac; Guia Prático, Histórico e Sentimental da cidade do Recife (1934), de Gilberto Freyre; Guia de Ouro Preto (1938), de Manuel Bandeira; e Babia de Todos os Santos - guia de ruas e mistérios (1945), de Jorge Amado. As conjecturas mais amplas deste estudo são: de que os literatos mensionados encontraram, no gênero literário do guia, tanto uma condição panorâmica quanto uma vocação para elaborar subjetividades, que os permitia acercar-se sobre questões e cidades que já os inquietavam, tocando-as nas suas superfícies e simultaneamente mergulhando em seu espírito, por intermédio de uma obra que tivesse largo alcance, uma vez que se destinava aos visitantes, mas não se limitava a eles; e, ainda, de que, ao produzirem suas obras a partir das cidades, dedicando sua atenção às cidades e à cultura, eles contribuíram ao mesmo tempo para uma elaboração do moderno e dos processos de modernização enquanto a modernidade expressa nessas cidades e na cultura também os afetava. Produzidos em diferentes momentos e debruçando-se sobre diferentes lugares, objetivamos sinalizar os possíveis cruzamentos entre tais publicações a fim de, comparativamente, sugerir aproximações e distanciamentos no tocante às motivações e incentivos para que tais produções se realizassem, analisar as diferentes perspectivas mobilizadas para apresentarem as cidades aos seus leitores, bem como avaliar possíveis relações entre essas obras, seus autores, o mercado editorial e a realização da atividade turística nesses distintos contextos. Muito embora a confluência de

1 Professora Doutora do Departamento de Turismo IGEOG/UERJ.E-mail: amandadanelli@ hotmail.com. 
publicações dessa espécie por intelectuais de renome no Brasil chame a atenção, observou-se que há escassa produção acadêmica sobre o tema e nenhuma que se tenha proposto a realizar essa investigação sob uma mirada comparativa, o que neste ensaio ganhará contornos incipientes.

Vale considerar ainda que o presente exercício textual tem interesse em contribuir para uma aproximação entre as investigações nos campos da História e do Turismo, em recente expansão, e aprofundar as interlocuções com as questões levantadas pela História Intelectual na América do Sul, em especial no que se refere às representações urbanas e às conexões entre cultura, cidades e literatos. Com isso, nossos esforços se inserem entre as investigações que vêm contribuindo para que as imagens turísticas de cidades brasileiras sejam postas em perspectiva histórica, observando-se a atuação dos mais distintos agentes para a formação, transformação e fixação delas.

\section{Percurso teórico e metodológico: diálogos em curso}

Desde 2013, perguntamo-nos sobre como a atual imagem turística da cidade do Rio de Janeiro - vinculada especialmente às paisagens monumentais e à beleza natural - teria se construído e, ainda, se essa imagem teria concorrido com outras imagens turísticas da cidade. Passamos, então, ao acervo da Biblioteca Nacional em busca de fontes que pudessem evocar as antigas representações associadas à cidade, encontrando nos guias e mapas de viagem tal característica documental. Mas não apenas: as crônicas e as notícias dos periódicos também nos ofereciam uma polifonia de interpretações sobre como a cidade era observada, experimentada e usufruída. Pouco a pouco, compreendemos que a cidade - além de tema de interesse dos literatos das primeiras décadas do século XX - era, para eles, o locus privilegiado para viver a experiência da modernidade, de modo que era a partir dessa dupla referência (cidade/modernidade) que eles se constituíam subjetivamente e refletiam sobre a modernidade na cidade. Assim, verificamos que, embora o guia operasse como um manual sem necessariamente fazer daquele suporte literário o lugar da produção de uma reflexão autêntica sobre a cidade, era no guia em que se reproduziam as representações sobre a cidade que os cronistas elaboravam nos jornais, revistas e conferências. $\mathrm{O}$ uso do guia como fonte para a produção de uma história cultural do turismo ou ainda uma história intelectual das representações sobre a cidade-capital estava, desde então, estreitamente orientada pela perspectiva apresentada a seguir: 
Propongo identificar, entonces, el espacio de articulación entre cultura urbana e historia cultural como el universo de representaciones que no solo tiene como tema la ciudad, sino que produce la ciudad, en el doble sentido: que es producido por la ciudad, y que la produce. El estudio cultural de la ciudad podría definirse, en esta dirección, como un estudio atento al modo en que la ciudad y sus representaciones se producen mutuamente (Gorelik, 1999, p. 210).

Naquele mesmo ano, travamos contato com o livro $A$ invenção de Copacabana, de Julia O'Donnell, no qual verificamos a exposição de evidências de que a invenção do bairro de Copacabana como um balneário estaria atrelada, entre outras coisas, à figura de Théo Filho e suas crônicas, que ensinavam aos moradores dos bairros atlânticos sobre os novos usos, hábitos, moda relacionados à praia como ambiente burguês de lazer e vida saudável. Já em 2015, conhecemos o livro Promenades do Rio, de Isabella Perrotta, que fez um amplo levantamento dos guias de viagem sobre o Rio publicados entre 1873 e 1939 - vale saber que alguns dos guias que compóem o acervo da Biblioteca Nacional, sobre o qual nos debruçamos, não foram elencados como objeto de investigação no livro acima citado. Por meio da extensa lista de guias, tomamos conhecimento do Guide des Etats Unis du Brèsil, de Olavo Bilac. Esses dois encontros - Théo Filho e Olavo Bilac - nos ajudaram a perceber que estávamos perseguindo uma importante pista na análise dos guias, associando-a à circulação dos intelectuais nas diversas redes de sociabilidades - salóes, livrarias, editoras, periódicos - e à simultânea experiência de viver e produzir sobre a moderna cultura urbana carioca.

É assim que percebo este ensaio como um pontapé para futuras investigações ligadas à História Intelectual e Cultural simultaneamente entrecruzado a uma perspectiva de interesse e interpretação que parte da cidade, portanto da cultura e dos problemas urbanos. Quanto há de cidade real e cidade ideal nessas páginas dos guias de viagens escritos por Bilac, Bandeira, Freyre e Amado? À exceção de Bandeira, que nem é mineiro nem se estabeleceu em Ouro Preto, todos os outros autores escreveram seus guias a partir de suas experiências urbanas precisamente nas cidades (para eles, misto de sujeito e objeto), experiências essas que não são apenas materiais, relativas à vida objetiva, mas que derivam de uma reflexão constante sobre o lugar que contribuiu para que eles se tornassem o que eram, chegando às questões que chegaram; lugares esses que eles ajudaram a transformar, quando não na sua carne - embora isso fosse possível - seguramente pela letra. 
Para esses intelectuais, a cidade é necessariamente vista como uma arena que coloca em questão a tensão entre vontade projetiva e existência real, como sugeriu José Luis Romero. Mais do que isso, seguindo a premissa que marcou as contribuições historiográficas de Angel Rama, em $A$ cidade das letras: não existiriam intelectuais se não existissem cidades. A apropriação desses autores por Adrián Gorelik nos demonstra como a cidade apresenta simultaneamente qualidades históricas e sociológicas, na medida em que é nela que se constrói um mercado editorial, um público leitor letrado e, portanto, um consequente impulso à profissionalização da intelectualidade.

En América, la modernidad fue un camino para llegar a la modernización, no su consecuencia; la modernidad se impuso como parte de uma política deliberada para conducir a la modernización, y en esa política la ciudad fue el objeto privilegiado. (Gorelik, 2003, p. 13)

Reconhecer o percurso que aproxima turismo, variadas políticas de estado em diferentes contextos e práticas do mercado editorial por meio dos guias nos coloca em contato, por um lado, com os distintos discursos sobre a nação brasileira nessas primeiras décadas do século XX e, por outro lado, com as variadas contribuições que o modernismo brasileiro deu para a construção retrospectiva (tradição) e prospectiva (futuro) dos próprios discursos acerca da nação, o que, no limite, nos aproxima da hipótese de que, no Brasil, o Estado, num determinado momento, teria atuado como figura de vanguarda (Gorelik, 2005).

\section{Guias de viagem e intelectuais brasileiros: aproximações iniciais}

Os guias de viagem, tal como os conhecemos hoje, começaram a ser produzidos no século XIX em resposta às mudanças que a atividade turística via se desenvolver ao longo daquele século, especialmente em decorrência dos avanços técnicos, que não apenas encurtaram o tempo das viagens e aumentaram o conforto durante os deslocamentos, mas que também interferiram nas formas de registro dessas viagens com o surgimento da fotografia, por exemplo. Se antes os guias se aproximavam frequentemente dos relatos de viagem, a partir do século XIX eles se diferenciaram daquele estilo de registro, aproximando-se cada vez mais da brevidade e velocidade das crônicas, implicando numa escrita mais objetiva, prática e utilitária. Visto dessa perspectiva, os guias se transformaram 
em um gênero panorâmico, que visava especialmente informar superficialmente sobre as cidades, conduzindo o leitor-viajante em segurança, sem estimular mergulhos nas tensões e paradoxos dos espíritos das cidades. Foi particularmente esse traço que conferiu ao guia o lugar de um gênero literário menor. Contudo, os guias continuaram convivendo com os relatos de viagem - que, além de descrições, muitas vezes ofereciam interpretações que ora revelavam e ora inventavam as cidades - e, ao passo que muitos guias se diferenciaram dos relatos, como já foi dito, outros se aproximaram daquele estilo.

Nos guias sobre os quais nos debruçaremos, é possível observar essa distinção: enquanto o guia de Olavo Bilac, publicado em 1904, resulta das relações entre as experiências de aceleração do tempo e velocidade/objetividade do registro, os demais guias publicados nos anos 1930 e 1940 dialogam com uma outra experiência da modernidade, que, ao ensejar reflexões sobre os seus limites, propicia aos intelectuais latino-americanos o íntimo contato com uma demanda epistemológica, cultural e política de construir as alternativas de futuro enquanto reelaboravam o passado.

Se os guias são férteis em construir imagens das cidades, tomadas ali necessariamente como destinos turísticos, seus autores são os pintores, arquitetos, cartógrafos que, a partir das suas experiências urbanas em suas cidades reais, elaboram a imagem da cidade ideal a ser visitada. De modo que é necessariamente a partir da dupla relação - intrínseca, se assim podemos dizer - de afetos e interpretações entre os intelectuais e a cidade, que eles a reinventam por meio de seus guias. A experiência na cidade, materialmente no decurso do passeio pelas suas ruas, é capaz de afetar e forjar constantes reelaborações das subjetividades, que por sua vez implicam em renovadas formas de experimentar e interpretar a própria cidade. Essas reelaborações de si e do espaço urbano estão estreitamente vinculadas com as experiências de deslocamento - objetivo e subjetivo - das viagens e dos viajantes. Os guias, portanto, intermediam essa relação que, a depender dos personagens envolvidos, pode se estabelecer tanto a partir do convite às superfícies como do estímulo aos mergulhos no espírito das cidades. Porque reconheciam em si próprios os efeitos desse deslocamento objetivo e subjetivo, os intelectuais responsáveis pela escrita desses guias, motivados por distintas questões, de diferentes formas, ultrapassaram o caráter prático e utilitário dos guias.

Ao passo que as transformações urbanas podem impactar na atividade turística que se realiza naquele local, também as mudanças no modo de se fazer 
turismo podem afetar o corpo e o espírito das cidades, além da forma como elas são organizadas e apresentadas. Nesse sentido, as transformações técnicas observadas ao longo do século XIX - especialmente nos transportes e nas comunicações - implicaram em uma nova forma de organização do turismo, contribuindo para a expansão da atividade com as viagens em grupo. Thomas Cook, um dos precursores dessa nova fase da atividade turística, foi então responsável pela popularização desse tipo de lazer, barateando os custos das viagens para o consumidor por meio da venda casada de trem e hotel - os primeiros pacotes de viagem -, assegurando a ocupação dos assentos e leitos das empresas de transporte e hospedagem. Com o avanço dos negócios, Cook estruturou a primeira agência de viagens, usando a publicidade para atrair seu público com o uso revistas e guias. Outros guias fizeram fama ao longo do século XIX, como o alemão Baedecker, comercializado até os dias de hoje.

Alguns historiadores localizam o início da atividade turística propriamente dita no Brasil justamente com a chegada ao Rio de Janeiro de um grupo de turistas organizados pela agência Cook \& Son, em 1908, feito noticiado em periódicos de grande circulação na época. A publicação de guias de viagem sobre a cidade-capital em fins do século XIX e nos primeiros anos do XX, entretanto, sugere que turistas - interessados em negócios ou lazer - já aportavam ali anos antes. Desde os primeiros anos republicanos, a imagem das cidades brasileiras que se apresentava ao estrangeiro, especialmente da então cidade-capital, figurou como tema relevante, tornando-se uma questão central para o presidente Rodrigues Alves (1902-06), que não poupou esforços em afastar o caráter de cidade-corte-colonial do Rio de Janeiro, a fim de que a sua atualização estética contribuísse para validar a participação do país no concerto das nações modernas. Sua preocupação política e econômica com o progresso material da capital, e por conseguinte do país, resultou na execução das reformas realizadas em parceria entre o executivo nacional e a prefeitura da cidade-capital, visando, em primeiro lugar, tornar o porto do Rio de Janeiro suficientemente seguro e bem articulado com as diferentes regiões da cidade, com o intuito de possibilitar a expansão dos negócios entre os locais e os estrangeiros dependentes da atividade portuária. Os investimentos na ampliação das trocas comerciais resultavam consequentemente em melhores condições, ao menos quanto à infraestrutura, para a chegada de negociantes e turistas. Assim, como já foi dito antes, as transformações do espaço urbano implicavam mudanças na atividade turística ali realizada. No entanto, sabemos que esses esforços tinham apenas como efeito secundário o turismo, uma vez que eram motivados por outros 
interesses. Nas primeiras décadas do século XX, se desconhece o planejamento mais complexo e integrado de políticas de estado destinadas ao turismo, de modo que a organização da atividade esteve fortemente vinculada às visões e ações do setor privado diretamente envolvido com esse campo.

A exposição internacional de 1922, comemorativa do centenário da independência, teve um papel relevante no modo como se passou a observar o tema do turismo no país, uma vez que a presença de visitantes brasileiros e estrangeiros, ao longo de um ano, contribuiu para a divulgação e fixação de uma imagem moderna da nação, bem como para a captação de divisas. Terminada a exposição, em alguns meses criou-se a Sociedade Brasileira de Turismo, associação privada e sem fins lucrativos, que visava protagonizar a organização da atividade no país, estimulando a realização de excursões internas, que deveriam "revelar o Brasil para os brasileiros", defesa que se fazia presente nas publicações de divulgação turística que eles editavam, como a Revista Brasileira de Turismo, publicada pela primeira vez em 1924 (Guimarães, 2013, p. 180). Além de estimular e promover ações de melhorias nas condições das estradas e da sinalização turística pelo país, a Sociedade Brasileira de Turismo representava o país no exterior em assuntos que envolviam essa área e reivindicava a normatização do setor pelo poder público. Em 1926, a sociedade se associou ao Touring Club, com sede na França, assumindo, a partir daí, o nome Touring Club Brasil.

Essa preponderância do Touring brasileiro nos assuntos turísticos que envolviam o Estado devia-se à falta de um órgão público específico para cuidar do turismo, o que só seria remediado a partir de 1934, com a criação do Departamento Geral de Turismo, ligado à Prefeitura do Distrito Federal, e melhor estruturado em 1937, com a estratégica inclusão de uma Divisão de Turismo numa das principais agências do Estado Novo, o Departamento de Imprensa e Propaganda. Ressalta-se ainda que, à frente desses dois departamentos que incluíram a promoção do turismo entre as suas principais incumbências, esteve Lourival Fontes, uma das figuras centrais da montagem do regime estadonovista. Isso nos permite falar numa visão estratégica do chefe do DIP acerca do turismo como um dos elementos primordiais na veiculação da propaganda da nação, dentro e fora do país (Guimarães, 2013, p. 180).

Outros elementos concorrentes nesse contexto dos anos 1920, 1930 e 1940 contribuíram para mudanças na atividade turística: em primeiro lugar 
as experiências das guerras mundiais dificultaram a circulação de turistas pelo mundo, impulsionando a atenção ao turismo interno, inclusive no Brasil; em segundo lugar, o ano de 1934 foi importante não apenas pela criação do Departamento Geral de Turismo, mas porque nacionalmente foi o momento de garantia legal de direitos trabalhistas, como as férias remuneradas, implicando o aumento do tempo livre e do grupo de possíveis consumidores das viagens como um tempo de lazer. Assim, as políticas de estado nos anos Vargas contribuíram triplamente para a ampliação, organização e divulgação da atividade turística no país. Nos termos do decreto de criação do DIP, a Divisão de Turismo tinha a função de superintender, organizar e fiscalizar os serviços de turismo interno e externo. Dessa forma, o departamento realizou esforços para aprimorar a estrutura turística do país, tendo atuado inclusive na mediação entre os governos dos estados e o Instituto dos Comerciários para a concessão de empréstimos destinados a construção de hotéis em diversas cidades. Entre as principais atribuições da Divisão de turismo do DIP, estavam: estimular a propaganda externa das paisagens e valores brasileiros; incentivar o turismo interno; registrar e fiscalizar as agências de viagens e de turismo, bem como todos os seus materiais de divulgação, tais como guias, roteiros e planos; além de dividir o país em zonas turísticas, unificar as empresas de transportes, promover facilidades aduaneiras, providenciar passaporte turístico, entre outras tantas. Com o objetivo de tornar o Brasil conhecido entre os norte-americanos - uma vez que a chegada de turistas europeus estava limitada pelo contex to das guerras -, o DIP investiu também em uma política editorial própria (e também em parceria com algumas editoras, como a José Olympio) produzindo e distribuindo internacionalmente revistas como a Travel in Brazil, escrita em inglês e organizada por Cecília Meireles, tendo circulado entre 1941 e 1943, contando com colaboradores ocasionais, como Mário de Andrade, José Lins do Rego, Sérgio Buarque de Holanda e Menotti Del Picchia. Mais do que apenas organizar a atividade turística, as políticas de estado nos anos 1930 integraram debates e ações em torno da nação, do moderno, da cultura, do patrimônio, da educação e da indústria, sendo o turismo e, aqui em especial, os guias de viagem uma das peças de articulação entre essas diversas esferas e agentes.

Como instrumento de articulação entre diferentes debates e ações que estiveram conjugadas, especialmente a partir dos anos 1930, os guias de viagem se apresentaram como um objeto relevante de análise. Em primeiro lugar, não podemos perder de vista que o guia é um gênero literário que chega a público 
por intermédio do mercado editorial, sobre o qual atuavam editoras privadas e órgãos públicos, como o Ministério da Educação e Saúde (MES), o Instituto Nacional do Livro (INL), o Serviço de Patrimônio Histórico e Artístico Nacional/Instituto do Patrimônio Histórico e Artístico Nacional (SPHAN/ IPHAN), e algumas vezes em parceria, conforme se deu com a José Olympio. O guia é também um artefato diretamente vinculado à atividade turística e, independentemente de como é elaborado, sempre oferece - em doses maiores ou menores - informações úteis ao turista, antecipando o que ele encontrará no destino. Para a realização da atividade turística, especialmente tomada do ponto de vista econômico, o guia é fundamental para a escolha dos meios de transporte e hospedagem, atrativos a serem visitados, restaurantes etc. Mas, para tanto, apesar da sua vocação totalizante, os autores dos guias produzem seleções, apresentam perspectivas, mesmo quando elas não são anunciadas. Desse modo, apesar de seu caráter prático e utilitário, os guias não são capazes de anular ou esconder a construção do olhar de seus autores e editores antes de contribuírem para a construção do olhar dos seus leitores-turistas. Aliás, havia naqueles anos a preocupação de formar um público-leitor no país, produzindo uma educação do olhar para determinadas questões caras à reelaboração das noções de nação e de cultura brasileiras atualizadas por agentes do estado em consonância com vários dos intelectuais modernistas, estivessem cooptados para o exercício ou colaboração com funções públicas ou não.

$\mathrm{O}$ convite à Gilberto Freyre e Manuel Bandeira por Rodrigo de Melo Franco e Andrade para que eles escrevessem guias é a constatação dessa lógica, mas é também o sinal de que se tratava de um momento favorável para empreitadas desse gênero. As seleções de Freyre e Bandeira se articulam com os debates acerca do que poderia, e mais do que isso, do que deveria ser identificado e selecionado como patrimônio nacional (e regional), de modo que os próprios guias se tornam um produto cultural da moderna nação.

Olavo Bilac e Jorge Amado estão nas margens da análise proposta e, a princípio, afastados da lógica que construímos acima. Entretanto, suas falas pelas ausências ou pelas diferenças em relação às citadas anteriormente - também com elas dialogam. Jorge Amado, assim como Gilberto Freyre e Manuel Bandeira, era um intelectual nordestino. Tal qual o sociólogo pernambucano, Amado foi editado nos anos 1930 pela José Olympio e fazia parte do amplo grupo de intelectuais modernistas que pautou o tema do regionalismo e contribuiu para que se forjasse a noção de nordeste brasileiro. Sua oposição ao gover- 
no Vargas significou, ao longo desses anos, duas prisões e um exílio no exterior. No retorno de Buenos Aires, sua prisão foi negociada de modo que ele cumpriu uma espécie de prisão domiciliar, ficando sua circulação limitada à Bahia. Justamente depois desse período de uma apreciação do país desde fora, seguida de uma intensa relação com o seu estado natal, Amado escreveu e publicou seu guia de ruas e mistérios da Bahia de Todos os Santos, que se debruça especialmente sobre as heranças das culturas africanas. Sobre essa particularidade, criou um registro de constante negociação entre heterogeneidades na cidade de Salvador, resultando dessa tensão expressões tão variadas que conjugam simultaneamente aflição e fascínio. A atenção do autor com o regionalismo, especialmente com o caráter baiano, não produziu necessariamente uma fala que concorria pacificamente para o discurso oficial, pretensamente uníssono, da moderna nação. Se para essa moderna nação o debate acerca da especificidade da cultura brasileira, da sua brasilidade, portanto, era fundamental entre os intelectuais e os representantes estadonovistas, o mesmo não ocorria com boa parte dos intelectuais do início do século XX. Eles, de modo bastante diverso, lidavam com um paradigma de nação que envolvia especialmente a necessidade de que essa sociedade se apresentasse interna e externamente suficientemente civilizada, em pé de igualdade com as nações europeias. Não era propriamente o que nos diferenciava que deveria ser sublinhado em nossa dinâmica sociocultural, mas precisamente o que nos equiparava às nações mais desenvolvidas que seria a razão do engrandecimento da nação brasileira. Os guias de Freyre, Bandeira e Amado foram publicados primeiramente em português. Destinavam-se, portanto, ao público de leitores-viajantes brasileiros - aliás, desde então, o turismo interno supera os números do turismo externo no Brasil. Já o guia de Bilac foi publicado em francês, abrindo o diálogo, em especial com o estrangeiro. Além disso, Bilac se esforçou em convencer o visitante da cidade-capital de que ele encontraria ali atrativos, lazeres e serviços tais quais se encontravam nos grandes centros europeus: praças, parques, monumentos, museus, clubes, teatros, cafés, confeitarias. Provavelmente o leitor do guia de Bilac seria um homem de negócios de passagem pelo Rio de Janeiro que aproveitaria parte do seu tempo livre para conhecer a cidade, seguindo as orientações do guia.

Em linhas gerais, o que está em jogo na observação comparativa desses quatro guias é a relação entre as diferentes apropriações que a experiência da modernidade brasileira permitiu em associação às diversas soluções que orientariam os processos de modernização; donde se observam variações tanto entre 
esses dois períodos, 1900-20 e 1920-40, como dentro de um mesmo período. $\mathrm{Na}$ medida em que os guias antecipam para o leitor-viajante o que deverá ser visto e valorizado, ele coopera para a legitimação de noções, paisagens e sociabilidades que, variando e se transformando de acordo com as condições de produção, se fixam e se legitimam como símbolos da cultura, seja ela local ou nacional. Especialmente quando tomados em perspectiva comparativa e lidos como chaves de interpretação do passado, os guias explicitam a dimensão plural e de conflito presente na construção das representações da cidade, de modo que, tal como sugere Nestor Canclini, o que cada grupo estabelece como bem nacional e relato legítimo de cada momento histórico "é o resultado de operações de seleção, combinação e encenação que mudam segundo os objetivos das forças que disputam a hegemonia e a renovação de seus pactos" (1997, p. 126).

\section{Considerações provisórias: apontamentos para o futuro}

A temática da produção de guias por intelectuais, da cultura urbana, do mercado editorial e da atividade turística envolve, necessariamente, diferentes campos do conhecimento, configurando-se como um tipo de reflexão de caráter interdisciplinar para o qual, neste ensaio, busca-se contribuir, especialmente com a inserção de uma perspectiva histórica. $\mathrm{O}$ desenvolvimento de investigações a partir do que fora proposto serão contribuições inéditas para a História do Turismo, por tratar de temas diferentes dos tradicionalmente estudados pela historiografia brasileira, considerando-se ainda a escassez de estudos que se interessam em observar o fenômeno do turismo e os variados artefatos a ele relacionados, como é o caso dos guias.

Observado o curioso fato de que importantes intelectuais brasileiros escreveram guias de viagem sobre diferentes cidades - o que, a princípio, não encontra paralelo em outros países latino-americanos -, vimos delineando uma série de perguntas que o presente ensaio pode apenas trazer à tona e principiar aproximações, deixando para o futuro o desenvolvimento das investigaçóes que apresentarão mais variados resultados: quais as motivações e incentivos esses intelectuais tiveram para escrever os guias? Qual o interesse dos intelectuais em investir em um gênero literário menor e incomum para eles? Qual a interferência da política do mercado editorial nesses diferentes contextos que pudesse justificar o interesse na publicação de guias? A escrita dos guias por esses intelectuais dialogava com seus demais interesses e produções literárias? Como as 
transformações na atividade turística ao longo dessas décadas afetavam a produção de guias? E, ao mesmo tempo, como a circulação de diferentes guias de viagem poderia afetar o olhar dos turistas, como as pessoas viajam e o que elas conhecem das cidades brasileiras? Teriam os guias, em algum nível (cívico, estético, histórico, geográfico), um papel pedagógico para o público de leitores-viajantes? Quais valores orientam o que deve ser selecionado e apresentado em um guia? Como a experiência da modernidade e do modernismo brasileiro estiveram relacionados à produção desses guias tais como eles se apresentaram? Quais outros agentes sociais, culturais e políticos poderiam estar relacionados à produção dos guias de viagem? Como e em que medida as políticas de estado, nessas primeiras quatro décadas e meia do século XX, poderiam interferir na produção e publicação de guias? Como esses guias escritos por intelectuais contribuíram (e ainda contribuem) para a formação e fixação das imagens turísticas dessas cidades?

\section{Referências}

AMADO, J. Bahia de Todos os Santos: guia de ruas e mistérios de Salvador. São Paulo: Companhia das Letras, 2012.

AZEVEDO, A. N. "A reforma Pereira Passos: uma tentativa de integração urbana". Revista Rio de Janeiro, n. 10, pp. 39-79, maio-ago. 2003.

AZEVEDO, N. P. Modernismo e regionalismo: os anos 20 em Pernambuco. João Pessoa: Ed. UFPB; Recife: Ed. UFPE, 1996.

BANDEIRA, M. Guia de Ouro Preto. São Paulo: Global, 2015.

BARREIRA, I. A. F. "Os guias turísticos em Berlim”. Tempo Social - Revista de Sociolgia da USP, v. 17, n. 1, pp. 299-321, 2005.

BENJAMIN, W. "Paris, capital do século XIX". In e KOTHE, F. R. Sociologia. Rio de Janeiro: Ed. Ática, 1991.

BILAC, O. Guide des Etats-Unis du Brèsil - Rio de Janeiro. Rio de Janeiro: Éditeurs Bilac, Passos \& Bandeira, 1904. 
BROCA, B. A vida literária no Brasil: 1900. Rio de Janeiro: Ministério da Educação e Cultura, 1956.

CANCLINI, N. G. Consumidores e cidadãos. Rio de Janeiro: Ed. UFRJ, 1997.

CARPEAUX, O. M. Retratos e leituras. Rio de Janeiro: Simões, 1953.

. Pequena bibliografia crítica da Literatura Brasileira. Rio de Janeiro: Serviço de documentação, Ministério de Educação e Cultura, 1955.

CHOAY, F. A alegoria do patrimônio. São Paulo: Ed. UNESP, 2001.

CHUVA, M. R. R. Os Arquitetos da Memória: sociogênese das práticas de preservação do patrimônio cultural no Brasil (anos 1930-1940). Rio de Janeiro: Ed. UFRJ, 2009.

CORREIA, E. B. "Guia de Ouro Preto e os poemas ouro-pretanos de Bandeira”. Signótica, v. 30, n. 1, pp. 29-51, jan./mar. 2018.

COSTA, A. D. "A cidade do Rio de Janeiro: cultura urbana e imagem turística". Acervo - Revista do Arquivo Nacional, v. 28, n. 1, pp. 186-95, 2015.

DIAS, S. M. V. “Gilberto Freyre e Manuel Bandeira nos anos 1920 e 1930: algumas experiências modernistas e suas aporias”. Revista Intellectus, ano 07, v. II, 2008.

. Cartas provincianas: correspondência entre Gilberto Freyre e Manuel bandeira. São Paulo: Global, 2017.

FERREIRA, T. A. O imaginário mistico e cultural da cidade da Babia: uma leitura de Babia de Todos os Santos: guia de ruas e mistérios, de Jorge Amado (dissertação). Universidade Estadual de Feira de Santana, 2013.

FREYRE, G. Guia prático, histórico e sentimental da cidade do Recife. São Paulo: Global, 2007.

. Olinda: 2. guia prático, histórico e sentimental de cidade brasileira. São Paulo: Global, 2007.

GIUCCI, G. e LARRETA, E. R. Gilberto Freyre: uma biografia cultural: a formação de um intelectual brasileiro: 1900-1936. Rio de Janeiro: Civilização Brasileira, 2007. 
GOMES, A. C. Estado Novo: ideologia e poder. Rio de Janeiro: Ed. FGV, 1982.

. "Estado Novo: ambiguidades e heranças de um regime autoritário". Ciência Hoje, v. 23, n. 133, Rio de Janeiro, nov. 1997.

. A invenção do trabalhismo. 3 ed. Rio de Janeiro: Editora FGV, 2005.

. "Educação, ciência e edição: consagração intelectual dos periódicos às coleções”. Revista Brasileira de História da Ciência, v. 7, n. 1, pp. 6-15, Rio de Janeiro, jan./jun. 2014.

GONÇALVES, J. R. S. A retórica da perda: os discursos do patrimônio cultural no Brasil. Rio de Janeiro: Ed. UFRJ: IPHAN, 2002.

GORELIK, A. "Historia de la ciudad e historia intelectual". Prismas - Revista de Historia Intelectual, n. 3, pp. 209-23, 1999.

. "Ciudad, modernidad, modernización”. Universitas Humanistica, n. 56, pp. 11-27, jun. 2003.

. Das vanguardas a Brasilia: cultura urbana e arquitetura na América Latina. Belo Horizonte: Ed. UFMG, 2005.

. "A produção da cidade latino-americana”. Tempo Social, Revista de Sociologia da USP, v. 17, n. 1, pp. 111-33, 2005.

e PEIXOTO, F. A. (comps.). Ciudades sudamericanas como arenas culturales. Buenos Aires: Siglo Veintiuno, 2016.

GOULART, S. Sob a verdade oficial: ideologia, propaganda e censura no Estado Novo. São Paulo: Editora Marco Zero, 1990.

GUIMARÃES, V. L. O turismo levado a sério: discursos e relações de poder no Brasil e na Argentina (1933-1946) (tese). Universidade Federal do Rio de Janeiro, 2012.

. "O turismo como vetor das relações Brasil-Argentina nas décadas de $1920 \mathrm{e}$ 1930”. Revista da ANPHLAC, n. 15, pp.175-97, 2013.

HALLEWELL, L. O livro no Brasil. Sua História. São Paulo: EDUSP/Queiroz, 1985. 
JORGE, F. Vida e poesia de Olavo Bilac. Osasco: Novo Século Editora, 2007.

LAFETÁ, J. L. 1930: a crítica e o Modernismo. São Paulo: Duas Cidades: Ed. 34, 2000.

LAJOLO, M. e ZILBERMAN, R. A formação da leitura no Brasil. São Paulo: Ática, 1996.

LANARI, R. A. O. Opatrimônio por escrito: a politica editorial do Serviço do Patrimônio Histórico e Artístico Nacional durante o Estado Novo (1937-45) (dissertação). Universidade Federal de Minas Gerais, 2010.

. "A cidade que não morreu: modernidade e tradição no guia de Ouro preto, de Manuel Bandeira”. Revista Científica das áreas de História, Letras, Educação e Serviço Social do Centro Universitário de Belo Horizonte, v. 6, n. 1, jan./jul. 2013.

LEITE, D. M. O caráter nacional brasileiro: história de uma ideologia. São Paulo: Ed. UNESP, 2002.

MAGALHÃeS JÚNIOR, R. Olavo Bilac e sua época. Rio de Janeiro: Companhia Editora Americana, 1974.

MEDEIROS, N. “A edição de livros como formulação do mundo: ideias e casos". Revista Brasileira de História da Mídia (RBHM), n. 2, v. 4, São Paulo, jul./dez. 2015.

MESQUITA, G. Gilberto Freyre e o Estado Novo: região, nação e modernidade. São Paulo: Global, 2018.

MICELI, Sérgio. Intelectuais à brasileira. São Paulo: Companhia das Letras, 2001. . Intelectuais e classe dirigente no Brasil (1920-1945). São Paulo: Difel, 1979.

O’DONNELL, J. A invenção de Copacabana. Rio de Janeiro: Ed. Zahar, 2013.

OLIVEIRA, I. V. "As viagens de Manuela Bandeira pela cidade de Ouro Preto". Guavira Letras, n. 10, pp. 41-50, ago./dez. 2010.

OLIVEIRA, L. L. "Gilberto Freyre e a valorização da província”. Revista Sociedade e Estado, n. 1, v.26, pp. 117-49, 2011. 
PÉCAULT, D. Os intelectuais e a politica no Brasil: entre o povo e a nação. São Paulo: Ática, 1990.

PEIXOTO, F. A. "A cidade e seus duplos: os guias de Gilberto Freyre". Tempo Social Revista de Sociologia da USP, v. 17, n. 1, pp. 159-73, 2005.

PERROTA, I. Promenades do Rio - a turistificação da cidade pelos guias de viagem entre 1973-1939. Rio de Janeiro: Topbooks, 2015.

POLZONOFF JÚNIOR, P. Manuel Bandeira: a vida toda que poderia ter sido, e foi. Rio de Janeiro: Relume Dumará: Prefeitura, 2006.

PONTES, H. "Retratos do Brasil: um estudo dos editores, das editoras, e das 'Coleções Brasilianas', nas décadas de 1930, 1940 e 1950”. Boletim Informativo e Bibliográfico de Ciências Sociais, n. 26, pp.56-89, 1988.

RAMA, A. A cidade das letras. São Paulo: Ed. Boitempo, 2015.

ROMANO, L. "Manuel Bandeira e Cecília Meireles em Ouro Preto”. Revista Turismo e Desenvolvimento, n. 27/28, pp.1127-39, 2017.

ROMERO, J. L. América Latina: as cidades e as ideias. Rio de Janeiro: Ed. UFRJ, 2009.

SÁ, M. E. N. (org.). História intelectual latino-americana: itinerários, debates eperspectivas. Rio de Janeiro: Ed. PUC-Rio, 2016.

SANTOS, M. V. M. "Nasce a Academia SPHAN". Revista do Patrimônio Histórico e Artístico Nacional, v. 24, 1996.

SANTOS FILHO, J. "O turismo na era Vargas e o Departamento de Imprensa e Propaganda - DIP”. Cultur - Revista de Cultura e Turismo, ano 02, n. 2, pp.1-14, 2008.

SAUNIER, P. Y. "Le guide touristique, un outil pour une possible histoire de l'espace: autor des guides de Lyon 1800-1914”. Géographie et cultures, L'Harmattan, n. 13, pp. 35-54, 1993.

SODRÉ, N. W. Orientações do Pensamento Brasileiro. Rio de Janeiro: Vecchi, 1942-43. 
SORÁ, G. "A construção sociológica de uma posição regionalista. Reflexões sobre a edição e recepção de 'Casa-grande \& senzala’ de Gilberto Freyre”. Revista Brasileira de Ciências Sociais, n. 36, pp.121-40, 1998.

. Brasilianas: José Olympio e a gênese do mercado editorial brasileiro. São Paulo: Ed. USP/Com-Arte, 2010.

SOUZA, G. M. “O mestre de Apipucos e o turista aprendiz." In: . Aideia e o figurado. São Paulo: Duas Cidades; Ed. 34, 2005.

VECCHI, R. "Recife como restos". Colóquio Letras, n. 157-158, p. 192, Lisboa, jul./ dez. 2000.

VELLOSO, M. P. "Cultura e poder político: uma configuração do campo intelectual (1930-1940)". In e OLIVEIRA, L. L. Os intelectuais e a politica cultural do Estado Novo. Rio de Janeiro: CPDOC/FGV, 1987.

VENTURA, R. Estilo tropical: história cultural e polêmicas literárias no Brasil,

1870-1914. São Paulo: Companhia das Letras, 1991.

VICENTE, S. M. "Leituras modernas da antiga província: nordestes, Gilberto Freyre e a vanguarda anglo-americana". Revista Terra Roxa e Outras Terras, Revista do Programa de Pós-graduação em Letras da Universidade Estadual de Londrina, n. 11, pp.77-90, Londrina, 2007. 